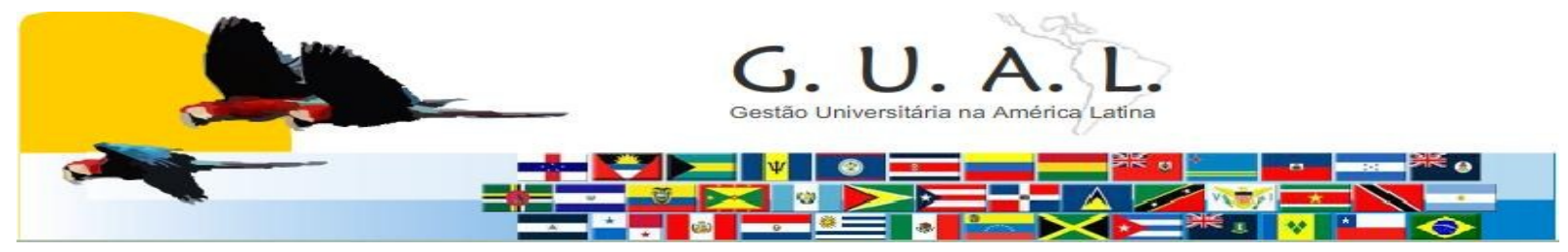

ISSN 1983-4535

\title{
GESTÃO DE RISCOS NAS UNIVERSIDADES E CENTROS UNIVERSITÁRIOS DO ESTADO DE SANTA CATARINA
}

\author{
Célia de Souza Sedrez, Bacharel \\ Centro Universitário de Brusque - UNIFEBE \\ celia@unifebe.edu.br
}

Francisco Carlos Fernandes, Doutor

Universidade Regional de Blumenau - FURB

franciscofernandes@furb.br

\begin{abstract}
RESUMO
O presente trabalho analisa e descreve a adaptação e aplicação de práticas de gestão de riscos e controles internos em instituições de ensino superior do Estado de Santa Catarina como suporte necessário ao controle das instituições. A pesquisa desenvolvida utiliza-se do método quantitativo e de corte seccional; quanto aos objetivos é do tipo descritiva, tendo como população os 5 Centros Universitários e as 12 Universidades do Estado de Santa Catarina. Os dados foram coletados através de questionário enviado aos gestores das IES. Os resultados da pesquisa evidenciam que a maior preocupação dos gestores, em termos de riscos está nas categorias de riscos estratégicos (fator principal: redução do número de alunos) e financeiros (fator principal: inadimplência). Por fim, conclui-se que, apesar da ausência de um sistema específico para apoio à gestão de riscos, as IES estão preocupadas com o assunto, mesmo não sendo ele ainda um assunto muito difundido e que as ações e os controles constatados por meio da pesquisa demonstram a preocupação dos gestores com a gestão de riscos nas suas instituições.
\end{abstract}

Palavras-chave: Gestão de riscos. Instituições de ensino superior. Controles internos. 


\section{GESTÃO DE RISCOS NAS UNIVERSIDADES E CENTROS UNIVERSITÁRIOS DO ESTADO DE SANTA CATARINA}

\section{INTRODUÇÃO}

As instituições de ensino superior - IES, como entidades com características peculiares, estão inseridas em um mercado que apresenta-se cada vez mais dinâmico e onde a concorrência é fator de grande preocupação. No Estado de Santa Catarina, a maioria das IES são classificadas como universidades ou centros universitários comunitários e sem fins lucrativos. Além disso, atuam num mercado em que dividem o espaço com as IES particulares (com fins lucrativos). A competição é um exemplo inequívoco de que uma IES, como qualquer empresa, também enfrenta riscos à continuidade de seus negócios.

Sendo instituições com características peculiares, que atuam em um mercado específico e que, assim, enfrentam riscos específicos, essas entidades necessitam de um adequado sistema de controle e gestão de riscos, para que possam aumentar a segurança da gestão, planejar suas metas conhecendo melhor os eventos que podem impedir seu cumprimento e, conseqüentemente, aumentar as chances de atingirem seus objetivos.

A pesquisa bibliográfica realizada demonstrou que há uma lacuna de trabalhos científicos que tenham abordado a gestão de riscos em instituições de ensino superior. O que se pretende com este estudo é avançar a pesquisa sobre o tema e verificar se as IES do Estado de Santa Catarina aplicam práticas de gestão de riscos e controles internos.

Para Bergamini Junior (2005), tem-se como definição de risco a possibilidade de ocorrência de um evento adverso para uma determinada situação esperada. As entidades precisam assumir e gerenciar riscos para gerar valor a seus acionistas (shareholders) ou interessados (stakeholders). As instituições sem fins lucrativos, que, à primeira vista, não parecem ter o mesmo nível de interesse em retornos financeiros, também necessitam ser rentáveis, no mínimo como uma forma de garantir sua sustentabilidade e até mesmo para manter seus projetos beneficentes. $\mathrm{Na}$ medida em que as atividades das organizações envolvam riscos, o gestor deve estar preparado para identificá-los, mensurá-los e avaliá-los. De acordo com Brito (2003), a gestão de risco é o processo por meio do qual as diversas exposições ao risco são identificadas, mensuradas e controladas.

A linha de raciocínio adotada neste trabalho é a de que essa gestão de risco é imprescindível para que as Instituições de Ensino Superior identifiquem os riscos a que estão expostas, medindo-os, controlando-os e adequando-os aos seus objetivos, que sempre devem ser entendidos como uma relação risco-retorno. Da mesma forma que qualquer entidade, as 
IES possuem objetivos e estruturas organizacionais e distribuem responsabilidades e competências, recursos e tecnologias, produzindo serviços demandados pela sociedade, assumindo riscos e buscando resultados. Para que isso ocorra de forma ordenada, é necessário que tais objetivos, ações e resultados, sejam integrados a uma adequada gestão de risco.

O objetivo geral deste estudo é analisar e descrever a gestão de riscos nas IES do Estado de Santa Catarina. Partindo do objetivo geral, elaboram-se os seguintes objetivos específicos:

a) averiguar se as IES do Estado de Santa Catarina possuem um sistema de gestão de riscos;

b) identificar quais são os riscos considerados mais importantes para as IES;

c) analisar, dentre os riscos identificados, qual ou quais, mais afetam as Instituições de Ensino Superior do Estado de Santa Catarina.

Para o alcance dos objetivos propostos, o trabalho foi dividido em três partes: revisão da literatura, descrição do método utilizado para a realização da pesquisa e, por fim, o estudo empírico que identifica quais os riscos que mais afetam as instituições de ensino do Estado de Santa Catarina.

Acredita-se que o estudo contribuirá para a linha de pesquisa sobre o Controle de Gestão e principalmente para a gestão de riscos e seu relacionamento com instituições de ensino superior.

\section{REVISÃO DA LITERATURA}

Destaca-se neste capítulo a fundamentação teórica do estudo, com a abordagem de gestão de riscos, sua relação com as instituições de ensino superior e as categorias de riscos.

\subsection{Gestão de riscos empresariais na atualidade}

Atualmente o gerenciamento de riscos empresariais tem sido referenciado com o apoio da metodologia do Commitee of Sponsoring Organizations of the Treadway Commission - COSO, um organismo não govenamental norte americano que surgiu a partir da National Commission on Fraudulent Financial Reporting, ou seja, a Comissão Nacional sobre Fraudes em Relatórios Financeiros, conhecida também como Treadway Commission, 


\section{GESTÃO DE RISCOS NAS UNIVERSIDADES E CENTROS UNIVERSITÁRIOS DO ESTADO DE SANTA CATARINA}

por ter como responsável James C. Treadway, ex-membro da Securities and Exchange Commission (SEC), que é a Comissão de Valores Mobiliários dos Estados Unidos.

Ferreira (2005) relata que o COSO é uma organização sem fins lucrativos dedicada à melhoria dos relatórios financeiros publicados pelas entidades, por meio da ética, efetividade dos controles internos e governança corporativa.

No ano de 1992, o COSO emitiu um relatório intitulado de Internal Control Integrated Framework, ou seja, "Estrutura Integrada de Controles Internos". De acordo com este relatório, inicialmente o objetivo principal era a definição comum de controles internos para que todas as entidades, independente da natureza jurídica, porte ou segmento, pudessem avaliar seus sistemas de controle, e procurar melhorá-los. Entende-se que o documento disponibilizado pelo COSO em 1992 veio para atender as necessidades das entidades.

Entretanto, mesmo após a publicação do relatório em 1992, conforme relata Almeida (2005), o Comitê continuou seus trabalhos e em 2001, nomeou um grupo de trabalho para liderar o desenvolvimento de um novo documento. Então, em setembro de 2004 o COSO disponibilizou à sociedade um novo documento, Enterprise Risk Management Integrated Framework. O COSO 2004 que foi constituído sobre as bases do Internal Control Integrated Framework. O novo documento descreve os componentes essenciais, princípios e conceitos da gestão de riscos para qualquer tipo de entidade.

Santos, Vasconcelos e Tribolet (2011) destacam que o modelo proposto pelo COSO, têm como foco toda a organização. De acordo com os autores, o COSO é aceito por grande parte dos profissionais de auditoria e, a adoção de uma estrutura efetiva sob o modelo COSO, aumentará as possibilidades de um sistema de informação confiável, ser usado pela gestão e pelo conselho de administração. Assim, o modelo proposto pelo COSO, contribuirá com a gestão da entidade.

Davis e Blaschek (2006) relatam que a estrutura apresentada pelo COSO 2004, mudou o conceito tradicional de controles internos e chamou a atenção de que estes controles tinham que fornecer proteção contra riscos e que os riscos mudariam com o passar do tempo. Sendo assim, as organizações tinham que monitorar os seus riscos e adequar os seus controles internos a uma nova realidade.

O fato é que o novo relatório publicado pelo COSO 2004 dá aos gestores e a toda a entidade uma visão mais profunda dos elementos que devem ser observados para culminar 
com obtenção dos objetivos e metas da organização.

Dessa forma, assim como o COSO (1992) Internal Control o COSO (2004)

Enterprise Risk Managemen Integrated Framework, desenvolve as três dimensões, conforme apresentado na Figura 1.

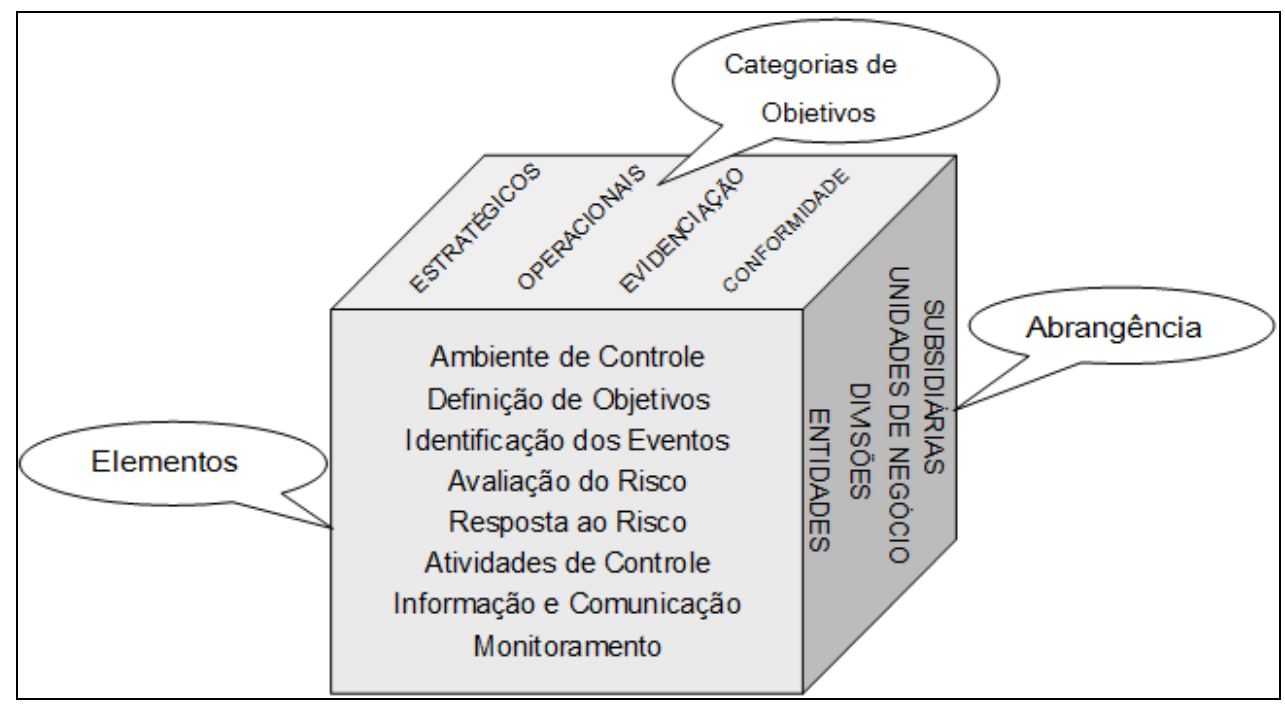

Figura 1 Elementos do COSO 2004

Fonte: Adaptado do COSO 2004

Como demonstrado na Figura 1, a primeira dimensão corresponde aos oito componentes da metodologia, a segunda dimensão corresponde às quatro categorias dos objetivos e a terceira dimensão relaciona-se à abrangência de aplicação da metodologia às diferentes unidades organizacionais da entidade.

A metodologia proposta pelo documento do COSO, Enterprise Risk Management Integrated Framework, objetiva auxiliar os dirigentes das entidades a trabalhar com os riscos inerentes ao alcance de seus objetivos. Este documento contém conceitos de gerenciamento de risco em um único modelo.

O novo relatório do COSO 2004 define uma estrutura para administração de risco e cria o que acredita-se tornar-se-á uma estrutura de ampla aceitação por discutir os riscos a partir do ponto de vista da administração.. Acredita-se que todos os contadores e gestores precisam entender este trabalho por completo, pois assim poderão ajudar as suas organizações a analisar e administrar os riscos a que a sua entidade estiverem expostas.

Para Gatto (2004), gerir riscos não significa evitá-los, até porque é tarefa impossível, mas, sim, reconhecê-los, tanto no ambiente interno, como no externo, analisá-los, mensurá-los 
e administrá-los de forma planejada e consciente. Dessa forma, o documento Enterprise Risk Management Integrated Framework (ERM) busca mitigar os riscos.

Ballou e Heitger (2005) inferem que todas as organizações podem beneficiar-se até certo ponto de administração de risco, não importando o seu tamanho. A estrutura de ERM é aplicável para companhias pequenas como também para empresas de médio e grande porte, desde que cada componente esteja presente e funcionando corretamente.

Para Campbell (2005, p. 2), o Enterprise Risk Management Integrated Framework (ERM) é considerado como um documento amplo de controle interno. E relata que:

O controle interno olhava tradicionalmente para a operação, relação financeira e conformidade dentro da organização. O ERM também olha para a organização, relação financeira e conformidade, mas é ampliado para cobrir todos os relatórios desenvolvidos por uma entidade e é distribuído internamente e externamente.

Paulo et al. (2007, p. 50) observam que:

Há, portanto, um problema de otimização da relação entre o nível de exposição desejado e os custos de implementação dos controles necessários. Considerações sobre a natureza desse problema são apresentadas pelo COSO (2004), que reconhece a existência de restrições de recursos, de tal forma que as empresas devem considerar os custos e os benefícios associados a cada alternativa de controle.

Neste sentido, a administração deve agrupar a redução de riscos da entidade considerando a relação custo-benefício e, sempre que possível, compartilhar as respostas encontradas. A identificação dos eventos permite à administração identificar riscos potenciais que afetam a realização dos objetivos da entidade, de forma positiva ou negativa. Eventos com impactos positivos representam oportunidades e são otimizados através da estratégia empresarial.

Para os fins deste trabalho, a metodologia do COSO é adotada primeiramente como referencial que demonstra a importância da gestão de riscos nas organizações. Mas especificamente, interessa para a pesquisa desenvolvida a caracterização do entendimento dos gestores das IES estudadas em relação aos riscos enfrentados, o que poderia ser entendido como uma forma de se acessar o "ambiente interno" dessas organizações.

O ambiente interno, por sua vez, é o primeiro dos oito componentes da metodologia do COSO e seu estudo é interessante porque é ele que "determina os conceitos básicos sobre a 


\section{GESTÃO DE RISCOS NAS UNIVERSIDADES E CENTROS UNIVERSITÁRIOS DO ESTADO DE SANTA CATARINA}

forma como os riscos e os controles internos serão vistos e abordados pelos empregados da organização" (COSO, 2004, p.3).

Para Rozo (2006) as diferentes categorias de risco têm ameaçado o desempenho e até mesmo a continuidade de muitas entidades, e tem despertado a atenção de administradores, instituições reguladoras, auditores internos e externos, contadores, controllers, para as questões relacionadas a controle sob a denominação comum de controle interno.

O necessário gerenciamento de risco é viabilizado pelos controles internos que são os pontos de detecção dessas ameaças e objetivam aumentar as chances de atingir os objetivos, reduzindo riscos. As entidades devem ter sistemas de controle interno, que proporcionem razoável confiança de que todas as transações são escrituradas adequadamente e em conformidade com políticas internas. Esta é proposta do COSO, que propõe uma revisão do entendimento dos controles internos, sustentando que já não podem ser entendidos somente como mecanismos que garantem a execução correta de um processo, nem tampouco como controles destinados à garantida de que os registros e relatórios contábeis estão corretos, mas sim como dispositivos que devem garantir que todos os riscos inerentes a um processo estejam dentro de patamares aceitáveis.

\subsection{Categorias de riscos}

O gerenciamento de risco é um processo lógico e sistemático para as organizações identificarem e avaliarem riscos e oportunidades, visando a uma melhor tomada de decisões e a avaliação de desempenhos. Apresenta uma visão para o futuro, isto é, não apenas evita ou minimiza perdas, mas lida positivamente com oportunidades (DAVIS, 2006).

Diante do desafio de gestão de riscos e controles internos nas empresas, uma estratégia utilizada é a de implementar ou aprimorar os controles internos baseados na identificação e mensuração dos riscos empresariais (CROUHY et al., 2004).

Esses riscos são especificados dentro de algumas categorias de risco, que entende-se ser necessário contextualizar. Os riscos a que as entidades estão expostas dependem da natureza de sua atividade alguns serão relatados a seguir: 


\section{GESTÃO DE RISCOS NAS UNIVERSIDADES E CENTROS UNIVERSITÁRIOS DO ESTADO DE SANTA CATARINA}

\subsubsection{Riscos operacionais}

Esses riscos são decorrentes de fraudes, erros de sistema de informações, extrapolação de autoridade dos colaboradores, desempenho insatisfatório, entre outros. Brito (2000, p. 70) destaca os riscos operacionais que "decorrem da falta de consistência e adequação dos sistemas de controle interno, sistemas de processamento e informações, o que pode ocasionar perdas inesperadas para a instituição".

Em relação aos riscos operacionais, Moraes (2003) relata a possibilidade de perdas associadas às atividades operacionais que envolvam fatores desiguais, como sistemas inadequados (informação ou suporte), falhas gerenciais, controles defeituosos ou inadequados, fraude ou erro humano e catástrofes.

Para os autores Crouhy et al. (2004, p. 475), risco operacional não é um tema pacífico na literatura. Isto acontece porque, segundo eles "[...] é difícil fazer uma clara distinção entre risco operacional e as incertezas 'normais' enfrentadas pelas organizações em suas operações diárias".

Gomes et al (2011) corroboram informando que vários autores e entidades reguladoras procuram definir risco operacional, sem, no entanto, haver na literatura uma uniformidade quanto a sua conceituação.

Carvalho (1999) destaca as causas de risco operacional, citando entre elas, contabilização ou manutenção inadequada dos registros, fraude, avaliação incorreta do valor de mercado, erro ao validar ou liquidar uma transação, falha no sistema de computação.

Diante dessas considerações, acredita-se que se a entidade tiver um sistema de controle de riscos operacionais eficiente, evitará a inadequação ou falhas, dos processos internos, pessoas ou processos externos.

\subsubsection{Riscos legais}

Destacam-se entre esses riscos a documentação incorreta das transações, descumprimento da legislação vigente, novas leis e decisões judiciais, que são decorrentes de questionamentos jurídicos referentes às transações efetuadas, contrariando as expectativas da instituição e tornando-se potencial fonte de perdas ou perturbações que podem afetar negativamente a organização.

Rev. GUAL., Florianópolis, Edição especial 2011, p.70-93. 


\section{GESTÃO DE RISCOS NAS UNIVERSIDADES E CENTROS UNIVERSITÁRIOS DO ESTADO DE SANTA CATARINA}

Moraes (2003) define como risco legal, a possibilidade de perdas decorrentes da inobservância de dispositivos legais ou regulamentares, da mudança da legislação ou de alterações na jurisprudência aplicáveis às transações da organização, como por exemplo, risco de legislação, que é a possibilidade de perdas decorrentes de sanções por reguladores e indenizações por danos a terceiros, em razão de violação da legislação ou regulamentos vigentes. Destaca-se também os riscos tributários, como sendo a possibilidade de perdas devido à criação, modificação, ou inadequada interpretação da incidência de tributos.

Percebe-se que a entidade precisa estar atenta em relação à legislação em vigor para não correr o risco de penalidades e sanções legais. Esses riscos podem levar inclusive ao comprometimento da reputação da entidade e a limitação das oportunidades de negócios.

\subsubsection{Riscos estratégicos}

O risco estratégico, segundo Marshall (2002, p. 436):

É o risco de se implementar uma estratégia mal sucedida ou ineficaz que fracasse em alcançar os retornos pretendidos. Muitos riscos estratégicos derivam de ameaças feitas por diferentes envolvidos no âmbito mais amplo da empresa, todos os quais têm objetivos e motivações potencialmente conflitantes.

Além disso, conforme Marshall (2002, p. 20), “a gestão do risco estratégico é inerentemente mais aberta e se baseia nas ferramentas e estruturas utilizadas por planejadores estratégicos (como a análise de cenários)".

Para Moraes (2003), risco estratégico é a possibilidade de perdas pelo insucesso das estratégias adotadas, levando-se em conta a dinâmica dos negócios e da concorrência, as alterações políticas no país e fora dele e as alterações na economia nacional e mundial.

Cocurulo e Vanca (2006) destacam como estratégicos, os riscos associados ao modo como uma organização é gerenciada. A gestão desses riscos é focada nas questões corporativas amplas, como fatores competitivos, estrutura organizacional, desenvolvimento de produtos, estratégia da formação de preços, entre outros.

São os riscos que têm origem em forças ambientais que estão fora do controle da entidade, mas que podem afetar o valor de ativos específicos ou a própria empresa como um todo. Algumas dessas forças são, por exemplo: 1) demandas de clientes ou fornecedores; 2) alterações nas características dos mercados de insumos ou de produtos, incluindo: a) entrada 


\section{GESTÃO DE RISCOS NAS UNIVERSIDADES E CENTROS UNIVERSITÁRIOS DO ESTADO DE SANTA CATARINA}

de novos produtos substitutos, e b) aumento da intensidade da concorrência através dos preços; 3 ) mudanças da regulamentação governamental, incluindo: a) regras contra a poluição ambiental, ou b) a criação de um novo tributo, dentre outros; 4) tecnologia, como, por exemplo, o surgimento de novas tecnologias de automação industrial; 5) políticas ou ambientes econômicos: recessão, expansão, alterações nas taxas de juros. (MARTIN et al., 2004).

Entende-se que risco estratégico pode ser definido como sendo a possibilidade de a entidade ser incapaz de se adaptar às mudanças que possam impedir o alcance dos objetivos planejados.

\subsubsection{Riscos de imagem}

Compreendem as perdas decorrentes da veiculação de informações que afetam negativamente a imagem ou a reputação da instituição, pondo em risco a manutenção de clientes e, conseqüentemente, a consecução de transações com esses clientes.

Risco de imagem pode ser definido como a possibilidade de perdas decorrentes de a instituição ter seu nome desgastado junto ao mercado ou autoridades em razão de publicidade negativa, verdadeira ou não (MORAES, 2003).

Entende-se que o risco de imagem decorre do impacto negativo da opinião pública em relação às atividades da entidade. Acredita-se que todo tipo de organização está sujeita a esses riscos e deve preocupar-se não somente com a sua imagem, mas também a de seus colaboradores, pois a reputação desses pode relacionar-se a imagem da organização.

\subsubsection{Riscos Financeiros:}

Estão associados à posição financeira de uma organização. A gestão de riscos financeiros está relacionada tanto ao uso de instrumentos financeiros relacionados à tesouraria e fluxos financeiros da organização quanto a eventos relacionados à elaboração e divulgação de relatórios financeiros (interno e externo).

Martin et al. (2004, p. 12) definem risco financeiro como:

Embora pudessem ser classificados entre os externos, tais riscos, dada a sua importância para as instituições financeiras e para a área financeira das empresas em geral, devem formar um agrupamento específico. São os riscos de mercado (referentes a movimentos desfavoráveis da taxa de juros, das 
taxas de câmbio ou de qualquer índice de reajuste dos preços de um contrato, bem como os que se referem às dificuldades ou incapacidade de transferir aumentos de custos para o mercado através dos preços), os riscos de crédito (relativos à incapacidade de um devedor de cumprir os termos de seu contrato) e os riscos de liquidez (relativos à impossibilidade de liquidar ativos ou de obter financiamento).

Acredita-se que o risco financeiro é um dos riscos que mais preocupam os gestores das entidades, pois, diante da situação de risco de liquidez e risco de crédito, a entidade pode não ter como operar e assim não poder honrar com o pagamento dos seus compromissos financeiros.

Dessa forma, as instituições de ensino superior, como entidades responsáveis pelo ensino, pesquisa e extensão, são organizações que despertam grande interesse de toda sociedade e estão expostas aos mais variados tipos de riscos. Essas entidades precisam estar atentas quanto ao gerenciamento de riscos para possibilitar o alcance de suas metas e suas estratégias.

Entretanto, para alcançar as suas metas, é necessário um adequado sistema de controle de seus recursos financeiros, físicos e humanos. Esses controles podem ser efetuados através da redução dos riscos, entre eles, os riscos estratégicos, financeiro, legal, de imagem e operacional, já relatados.

Assumindo as premissas de que as IES submetem-se a riscos e que estes devem ser geridos, esta pesquisa busca esclarecer se as IES vêm fazendo uma boa gestão de riscos, ou se ainda não despertaram para o problema.

\section{PROCEDIMENTOS METODOLÓGICOS}

Compreende-se como método, as diversas etapas ordenadas que são desenvolvidas ao longo de uma investigação com o objetivo de atingir o resultado desejado. Segundo Richardson (1999), método em pesquisa corresponde à escolha de certos procedimentos sistemáticos para a descrição e explicação de fenômenos. De acordo com Cervo e Bervian (2002, p.185), “o método científico é a ferramenta colocada à disposição do cientista que, com a pesquisa, pretende penetrar no segredo do seu objeto de estudo". Em seu sentido geral, o método é o ordenamento que se deve auferir aos vários processos que são necessários para alcançar determinado fim estabelecido, (BEUREN, 2006). 
A pesquisa desenvolvida utiliza-se do método quantitativo e de corte seccional. Quanto aos objetivos, a pesquisa é do tipo descritiva, tendo como população os 6 Centros Universitários e as 13 Universidades do Estado de Santa Catarina. Para o delineamento da pesquisa foi seguida a classificação proposta por Santos (1999), que apresenta três critérios: quanto aos objetivos, descritiva, quanto aos procedimentos de coleta, documental e de levantamento, e quanto às fontes de informação, pesquisa de campo.

O questionário foi elaborado com base em entrevistas dos pesquisadores com diversos profissionais da gestão de instituições de ensino superior. Posteriormente foi realizado um pré-teste do instrumento de pesquisa com o controller da Faculdade de Itapiranga (Sei-Fai). Depois de testado, o instrumento foi aplicado nas demais IES. O questionário foi elaborado contendo 18 perguntas fechadas e uma aberta. Dos 19 questionários enviados às IES, foram obtidas 14 respostas. Para este estudo foram consideradas as 7 questões relacionadas com a importância relativa dos diversos riscos associados a cada categoria e os sistemas de apoio à gestão de riscos.

\section{DESCRIÇÃO E ANÁLISE DOS DADOS}

$\mathrm{Na}$ análise dos resultados da pesquisa, verificou-se junto aos pesquisados se as IES adotam algum sistema de gestão de riscos, qual a importância dos riscos estratégicos, financeiros, legais, imagem e operacionais, qual a satisfação dos respondentes em relação ao controle desses riscos e também a importância dos referidos riscos para a instituição.

Neste sentido, a primeira questão do tópico relacionado à gestão de riscos, perguntava se as IES adotam algum sistema de gestão de riscos. As respostas a essa questão são apresentadas na Figura 2.

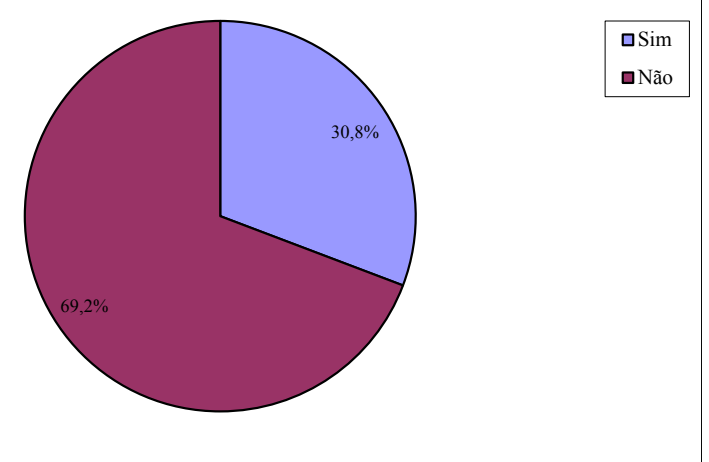

Figura 2 Instituições de ensino superior que adotam gestão de riscos Fonte: dados da pesquisa.

Rev. GUAL., Florianópolis, Edição especial 2011, p.70-93. 


\section{GESTÃO DE RISCOS NAS UNIVERSIDADES E CENTROS UNIVERSITÁRIOS DO ESTADO DE SANTA CATARINA}

A maioria das IES, sendo 9 delas responderam que não adotam nenhum sistema de gestão de riscos, somente 4 dos respondentes afirmou que a instituição adota algum sistema de gestão de riscos, uma das IES não respondeu a questão.

Essas respostas evidenciam que o desenvolvimento de abordagens próprias à gestão de riscos nas IES pesquisadas é um desafio a ser enfrentado no curto prazo, porque elas admitem não ter sistemas de gestão e controle do risco, mas admitem a existência de diversos riscos, como poderá ser observado.

A pesquisa também procurou verificar dentre as categorias de riscos estratégico, financeiro, de imagem, legal e operacional, qual o risco que mais afeta a IES, no tópico seguinte serão apresentados esses dados.

\subsection{Riscos Estratégicos}

$\mathrm{Na}$ pesquisa solicitou-se que os participantes enumerassem, em ordem de importância, os diversos riscos estratégicos, atribuindo 1 para o mais importante e 5 para o menos importante. As respostas podem ser observadas na Figura 3.

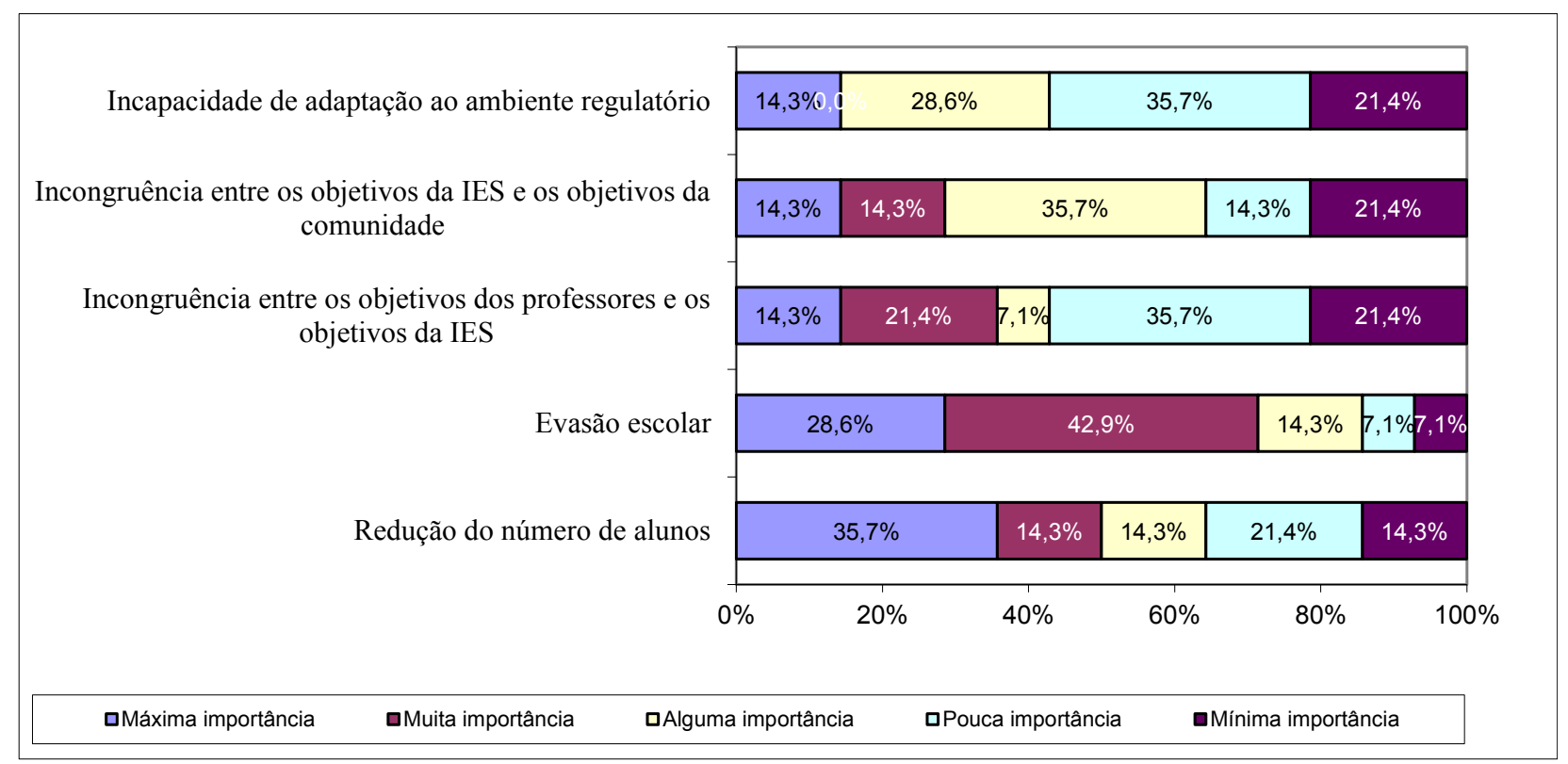

Figura 3 Importância dos riscos estratégicos

Fonte: dados da pesquisa. 


\section{GESTÃO DE RISCOS NAS UNIVERSIDADES E CENTROS UNIVERSITÁRIOS DO ESTADO DE SANTA CATARINA}

Percebe-se por meio da análise das respostas em relação aos riscos estratégicos, que os principais riscos que afetam as IES são a redução do número de alunos, onde 5 dos participantes consideram como sendo o risco mais importante representando $35,7 \%$. Na seqüência, apresenta-se, de acordo com os dados da pesquisa, o segundo risco estratégico considerado mais importante, que é a evasão escolar. Neste item, 4 respondentes apontaram como sendo o principal risco e 6 respondentes consideraram o segundo maior risco em termos estratégicos. No conjunto, a evasão escolar representa $71,5 \%$, sendo que $28,6 \%$ dos respondentes consideram de máxima importância e 42,9\% de muita importância.

Como uma forma de sondar os aspectos relacionados à gestão dos riscos estratégicos, procurou-se verificar quais variáveis são consideradas quando da implantação de um novo curso, essa questão era de múltipla escolha. O respondente poderia assinalar mais de uma opção. A Figura 4 apresenta as freqüências observadas nas escolhas de cada uma das alternativas.

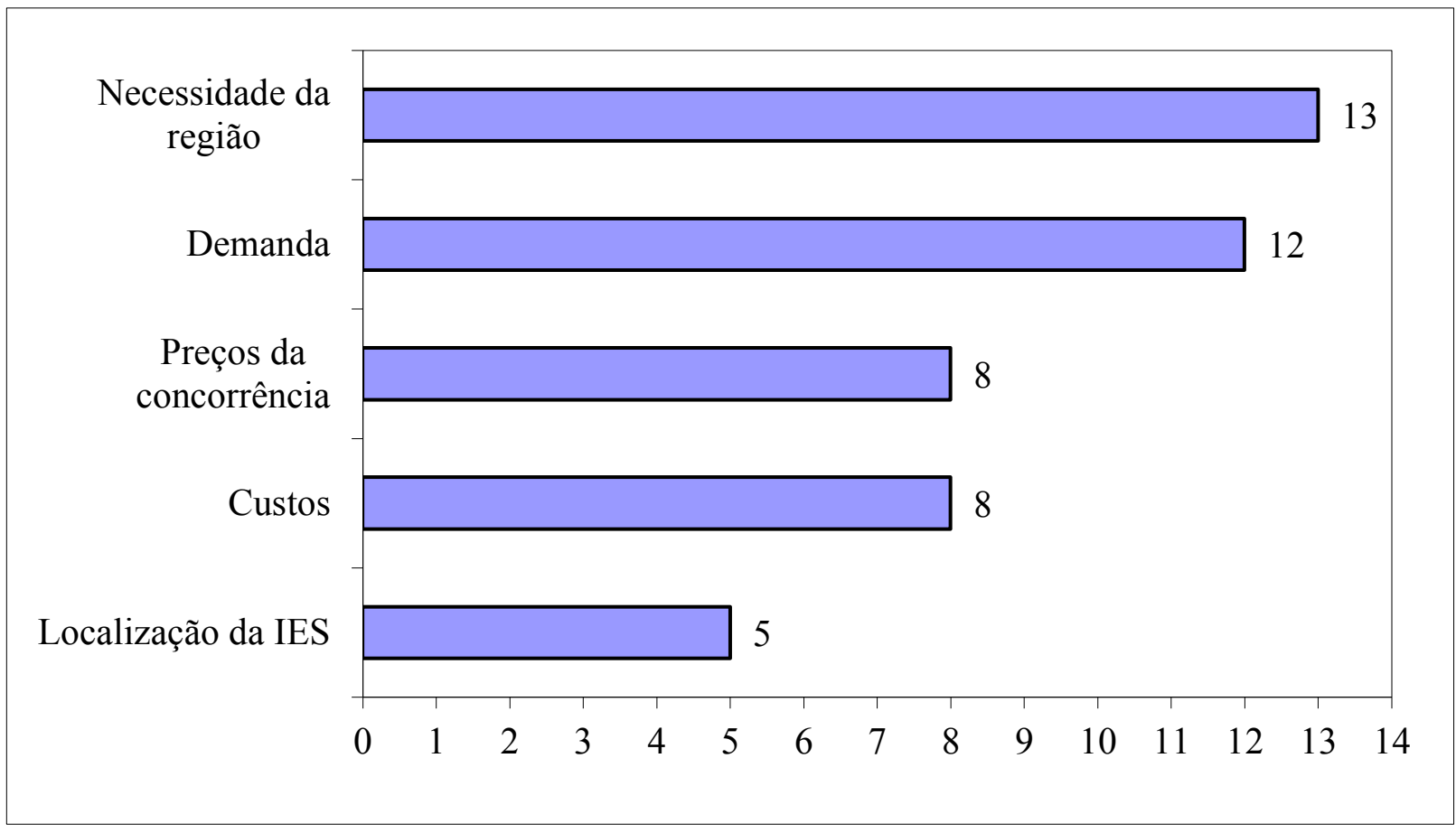

Figura 4 Variáveis que são consideradas pelas IES para implantar um novo curso Fonte: dados da pesquisa. 


\section{GESTÃO DE RISCOS NAS UNIVERSIDADES E CENTROS UNIVERSITÁRIOS DO ESTADO DE SANTA CATARINA}

Conforme demonstrado pela Figura 4 as IES verificam primeiramente a necessidade da região, seguida da demanda pelos cursos a serem ofertados. Itens como custos e preços praticados pela concorrência também são variáveis observadas pelas IES.

Pode-se inferir, observando as respostas dos gestores das instituições, que, buscando atender às necessidades da região, as IES estão também fazendo a sua parte social, desenvolvendo a região a qual estão inseridas.

\subsection{Riscos Financeiros}

Em relação à questão da pesquisa que solicitava que os respondentes enumerassem em ordem de importância os diversos riscos financeiros, atribuindo 1 para o mais importante e 5 para o menos importante, poderia ser atribuído o mesmo grau de importância a mais de um risco financeiro. Os dados são apresentados na Figura 5.

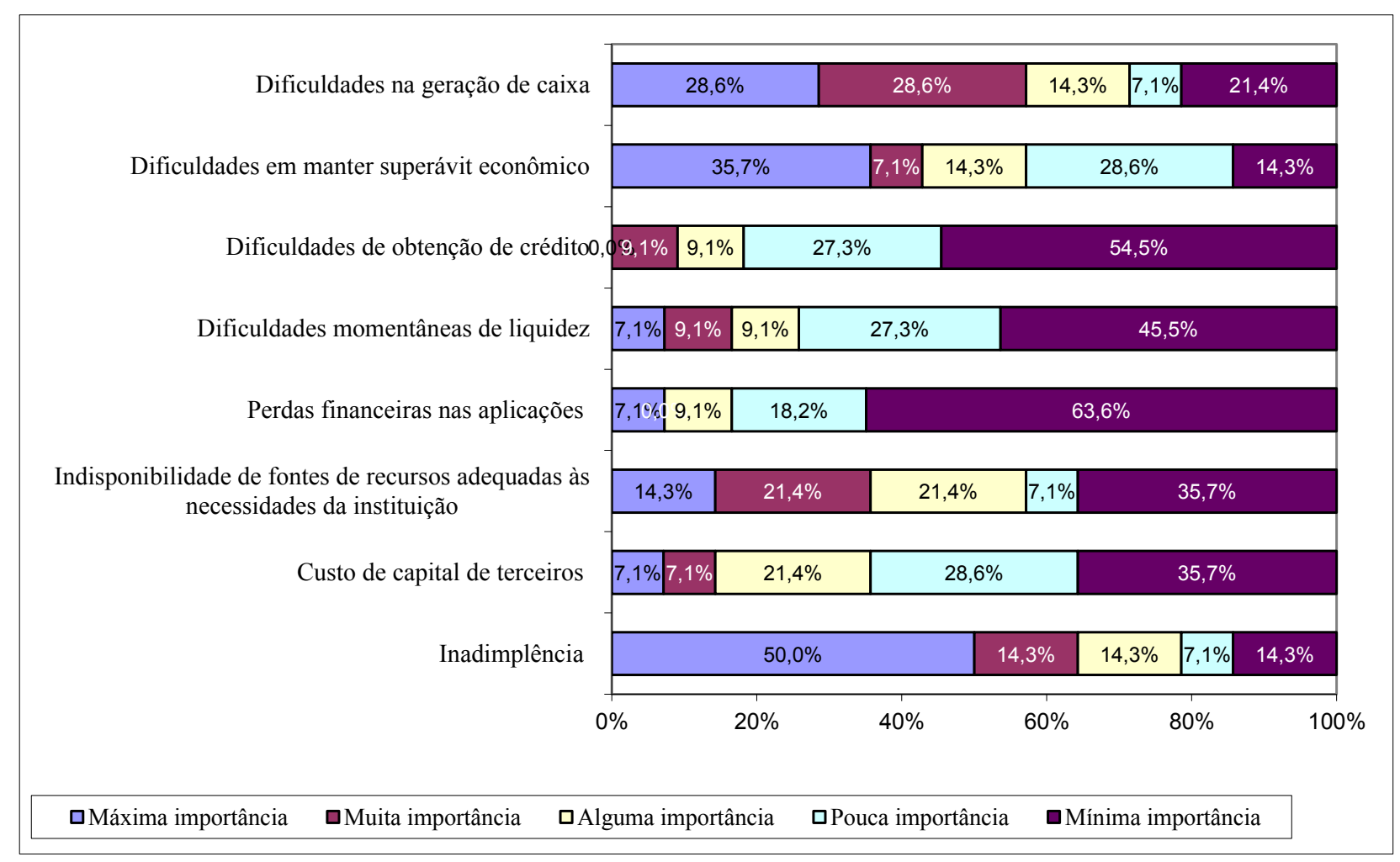

Figura 5 Importância em relação aos riscos financeiros Fonte: dados da pesquisa.

As respostas apontam que os pesquisados consideram a inadimplência como sendo o risco financeiro mais importante. O item recebeu 7 repostas em primeiro lugar, 2 em segundo, 2 em terceiro e 2 em quinto, representando $50,0 \%$. 


\section{GESTÃO DE RISCOS NAS UNIVERSIDADES E CENTROS UNIVERSITÁRIOS DO ESTADO DE SANTA CATARINA}

Entende-se essa preocupação dos gestores das IES a respeito da inadimplência dos alunos, pois, na maioria das instituições as mensalidades pagas pelos alunos é a sua única fonte de recurso para manterem suas estruturas físicas, humana e investirem em salas de aulas, laboratórios, acervo bibliográfico, entre outros.

Ao analisar individualmente os questionários, observa-se que mesmo no caso das instituições públicas, também existe a preocupação com a inadimplência. Observou-se que uma das IES que está na condição de entidade pública considerou a inadimplência como sendo o risco financeiro mais importante, neste caso seria a falta de repasses dos recursos por parte do governo estadual ou federal ao qual a instituição estiver vinculada.

A Universidade do Estado de Santa Catarina - UDESC e a Universidade Federal de Santa Catarina - UFSC, encontram-se nessa condição, diferenciando-se das demais IES, por ser de responsabilidade do Estado e do Governo Federal, e oferecerem seus cursos sem a cobrança de mensalidades, mas dependem dos repasses dos Governos Estadual ou Federal para cumprirem com suas obrigações financeiras.

\subsection{Riscos Legais}

Solicitou-se junto aos sujeitos da pesquisa, que enumerassem em ordem de importância os diversos riscos legais. Como nas questões anteriores, pedia-se aos respondentes que atribuíssem 1 para o risco considerado mais importante e 5 para o risco considerado menos importante. Os resultados são demonstrados na Figura 6.

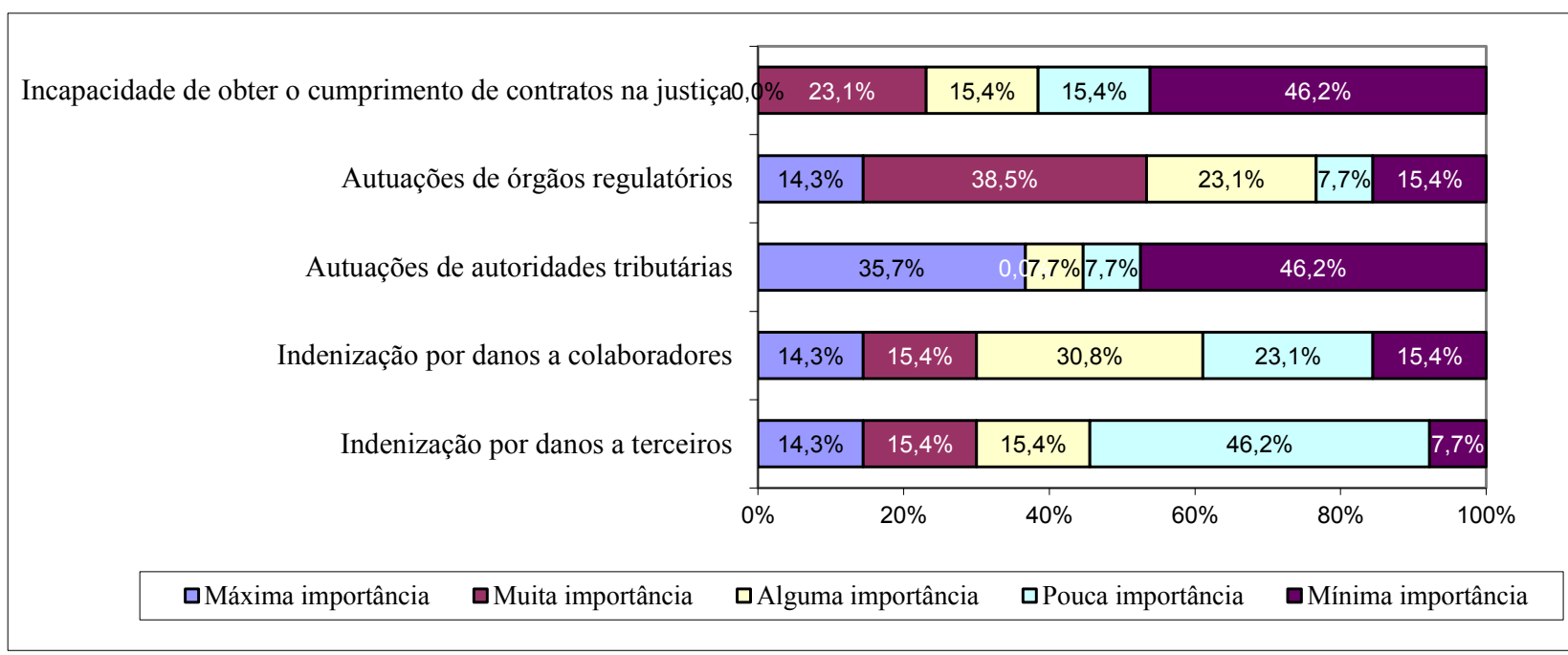

Figura 6 Importância em relação aos riscos legais Fonte: dados da pesquisa.

Rev. GUAL., Florianópolis, Edição especial 2011, p.70-93. 


\section{GESTÃO DE RISCOS NAS UNIVERSIDADES E CENTROS UNIVERSITÁRIOS DO ESTADO DE SANTA CATARINA}

Como demonstrado nas respostas, os pesquisados consideram como sendo o risco legal mais importante a autuações de autoridades tributárias, com 5 respostas em primeiro lugar, representando 35,7\%. Percebe-se que, enquanto para alguns gestores a autuação de autoridades tributárias é considerada como o risco legal mais importante, outros 46,2\%, consideram como sendo o risco de mínima importância.

Verificando as respostas dos respondentes, nota-se que no conjunto o item autuações dos órgãos regulatórios, representa $52,8 \%$, sendo que $14,3 \%$ dos respondentes consideraram como sendo o risco de máxima importância e 38,5\% de muita importância. Observa-se nesta questão que 1 das IES não respondeu a pergunta.

\subsection{Riscos de Imagem}

$\mathrm{Na}$ questão da pesquisa, que trata dos riscos de imagem, buscou-se saber junto aos pesquisados quais os riscos de imagem que são considerados mais importantes para a instituição, atribuindo também a numeração de 1 para o mais importante e 5 para o menos importante, conforme Figura 7.

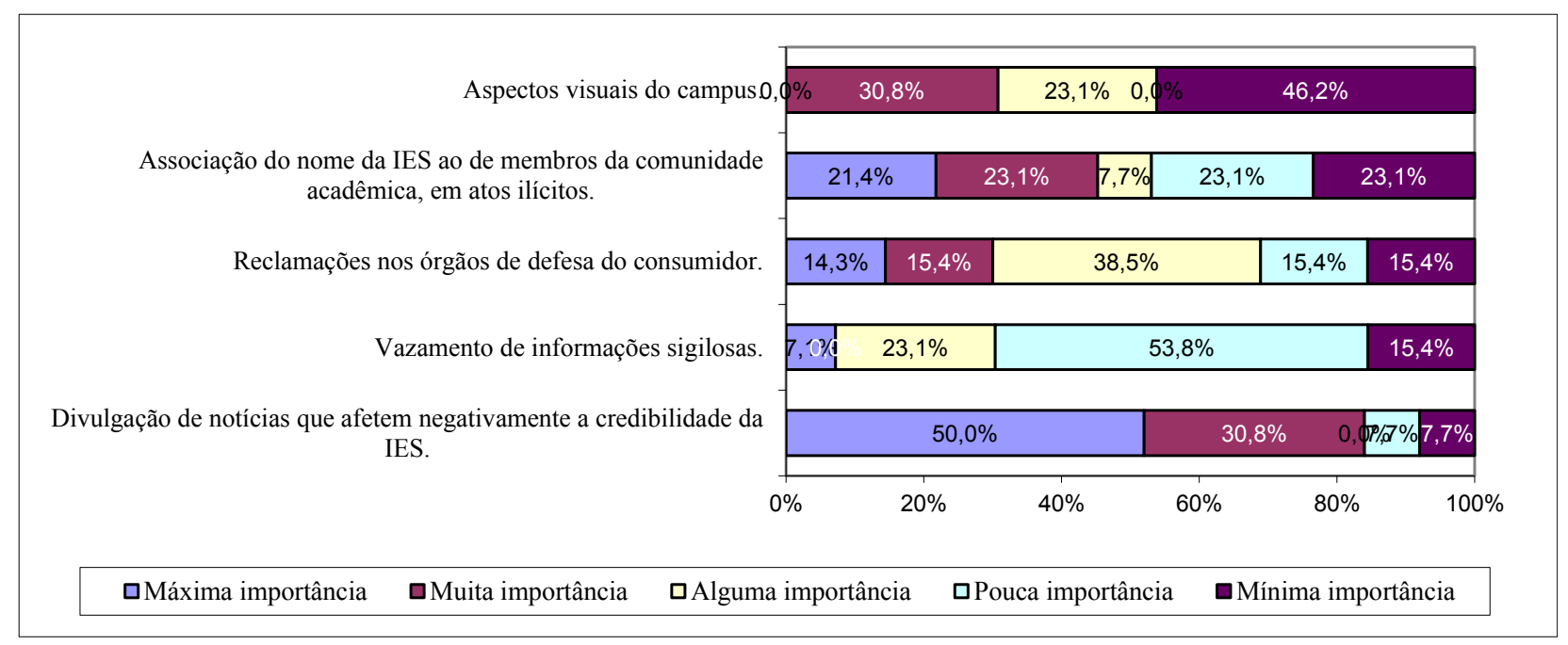

Figura 7 Importância em relação aos riscos de imagem Fonte: dados da pesquisa.

Em relação a essa questão, observa-se que a apreensão dos gestores das IES está relacionada à divulgação de notícias que afetam negativamente a credibilidade das instituições. Esse item recebeu 6 respostas em primeiro lugar, 3 em segundo lugar e 1 resposta 


\section{GESTÃO DE RISCOS NAS UNIVERSIDADES E CENTROS UNIVERSITÁRIOS DO ESTADO DE SANTA CATARINA}

em quarto e quinto lugar, somando $50 \%$, percebe-se que este item soma $80,8 \%$, se considerarmos que 50\% dos respondentes considerou como sendo de máxima importância e $30,8 \%$ de muita importância.

$\mathrm{Na}$ seqüência, o item associação do nome da IES ao de membros da comunidade acadêmica, em atos ilícitos ficou em segundo lugar. Itens como aspectos visuais do campus, foram consideradas de "pouca importância" pelos respondentes.

\subsection{Riscos Operacionais}

A pesquisa também procurou verificar junto aos respondentes qual a importância que eles atribuem aos riscos operacionais. Assim como nas questões anteriores, pedia-se aos pesquisados que enumerassem em ordem de importância os diversos riscos operacionais, atribuindo 1 para o mais importante e 5 para o menos importante. As respostas são apresentadas pela Figura 8.

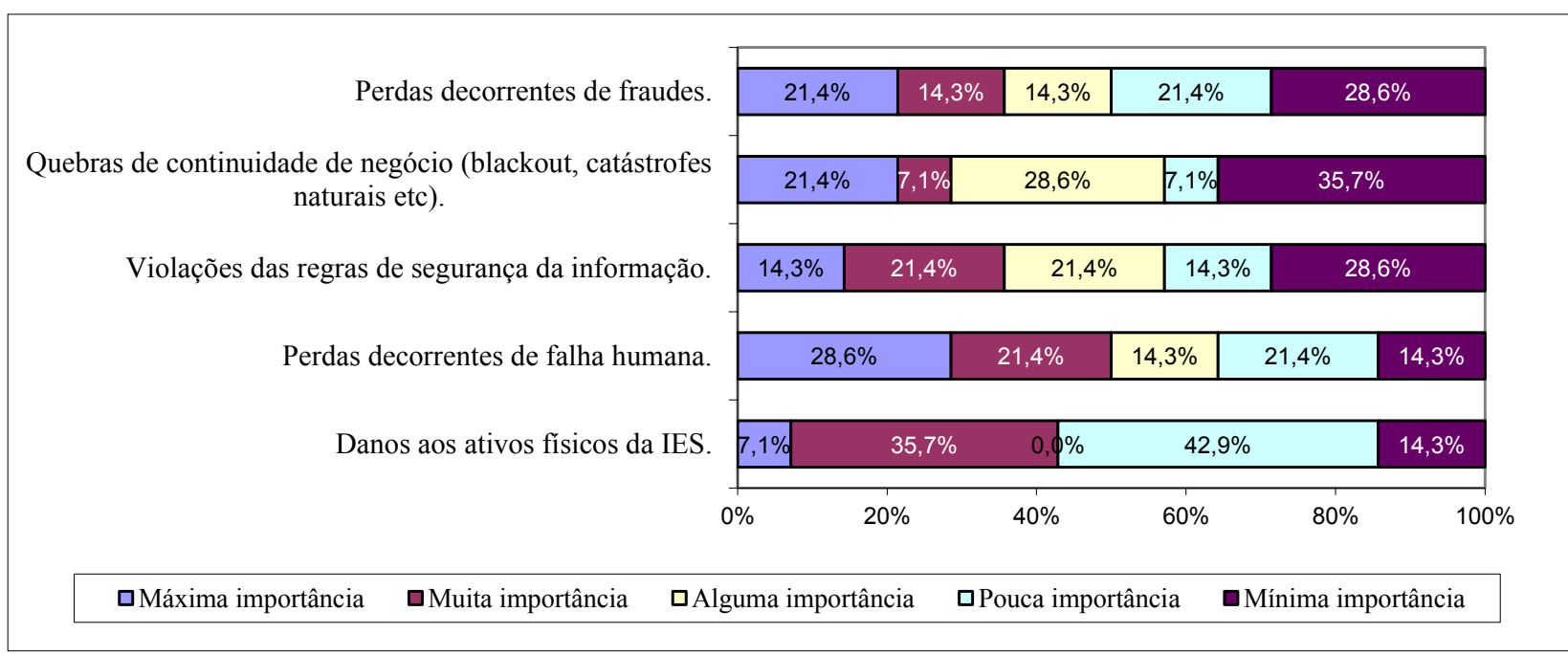

Figura 8 Importância em relação aos riscos operacionais Fonte: dados da pesquisa.

Baseando-se nas respostas obtidas, percebe-se que o risco considerado mais importante na visão dos pesquisados, são as perdas decorrentes de falha humana, com $28,6 \%$. Este item recebeu 5 respostas em primeiro lugar, 3 em segundo, 2 respostas em terceiro, $3 \mathrm{em}$ quarto e 1 em quinto lugar. Seguida de perdas decorrentes de fraudes, que no conjunto soma $35,7 \%$, sendo que 21,4\% dos gestores consideram de "máxima importância" e 14,3\% de "muita importância".

Rev. GUAL., Florianópolis, Edição especial 2011, p.70-93. 


\section{GESTÃO DE RISCOS NAS UNIVERSIDADES E CENTROS UNIVERSITÁRIOS DO ESTADO DE SANTA CATARINA}

Observa-se pelos dados da Figura 8, que um dos itens de menor importância considerada pelos gestores das IES está relacionado aos ativos físicos, talvez a tranqüilidade dos gestores em relação a este item, seja devido ao fato de às instituições já estarem protegendo-se por meio de vigilância e seguros dos ativos, procurando dessa forma a redução desses riscos.

A última questão da pesquisa era descritiva e pedia aos respondentes para fazerem seus comentários a respeito da pesquisa e/ou da gestão de riscos na sua IES e $57 \%$ dos participantes, deixaram seus comentários. A maioria dos gestores considerou interessante a pesquisa e parabenizou pela realização da mesma, mostrando-se interessada em conhecer a situação das Instituições de Ensino Superior do Estado de Santa Catarina, no que diz respeito à gestão de riscos. Os respondentes comentaram também, que a pesquisa servirá de parâmetro aos gestores, e que os resultados poderão trazer subsídios importantes para orientá-los na tomada de decisão. Um dos gestores destacou que "é necessário estar atento aos riscos inerentes à atividade, para evitar surpresas". Por fim, os respondentes mostraram-se interessados em saber o resultado da pesquisa.

\section{CONSIDERAÇÕES FINAIS}

O estudo realizado propôs-se a analisar e descrever a gestão de riscos nas IES do Estado de Santa Catarina. Procurando averiguar se as IES do Estado de Santa Catarina possuem um sistema de gestão de riscos. Os resultados apontaram 69,2\% das Instituições de Ensino Superior do Estado de Santa Catarina não adotam nenhum sistema de gestão de riscos. As respostas evidenciam que o desenvolvimento de abordagens próprias à gestão de riscos nas IES pesquisadas é um desafio a ser enfrentado no curto prazo.

Através do estudo pode-se analisar, dentre os riscos identificados, qual ou quais, mais afetam as Instituições de Ensino Superior do Estado de Santa Catarina. A pesquisa possibilitou constatar que em relação aos riscos estratégicos o risco considerado mais importante, e que mais afeta as IES é a redução do número de alunos. É compreensível esta preocupação dos respondentes em relação à redução do número de alunos sendo que na maioria das IES pesquisadas, a única fonte de recurso é proveniente das mensalidades pagas pelos alunos.

Rev. GUAL., Florianópolis, Edição especial 2011, p.70-93. 


\section{GESTÃO DE RISCOS NAS UNIVERSIDADES E CENTROS UNIVERSITÁRIOS DO ESTADO DE SANTA CATARINA}

Verificou-se por meio da pesquisa que o risco financeiro considerado mais importante e que mais afetam as IES, é a inadimplência. Infere-se através do resultado da pesquisa, que assim como a preocupação dos gestores em relação aos riscos estratégicos está relacionada à redução do número de alunos, o risco financeiro refere-se à inadimplência. Percebe-se que nas duas situações, ou ocorrendo redução do número de alunos, ou a inadimplência, faltará recursos para as IES fazerem frente aos seus compromissos financeiros.

Em relação aos riscos legais, observou-se que as "autuações de autoridades tributárias", foi considerado o risco mais importante pelos gestores. Percebe-se por meio dos resultados da pesquisa a preocupação dos gestores das IES relacionadas às autoridades tributárias, pode-se inferir que os gestores não estão completamente satisfeitos em relação aos controles dos riscos legais.

Tratando-se dos riscos de imagem, evidenciou-se que o risco de "divulgação de notícias que afetam negativamente a credibilidade da instituição" é considerado mais importante e os que mais afetam as IES. Por meio da pesquisa é possível constatar a relação entre os riscos definidos como os que mais afetam a instituição, certamente ocorrendo notícias que afetam negativamente a imagem das IES, poderá haver uma redução do número de alunos e conseqüentemente a IES poderá ter problemas financeiros.

Observou-se por meio da pesquisa que na categoria riscos operacionais a variável "perda decorrente de falhas humanas" foi considerada pelos gestores como a mais importante. Destaca-se então a importância do treinamento e do comprometimento dos colaboradores apontados pela gestão de riscos.

Por fim, conclui-se que, de maneira geral, as IES estão preocupadas com a gestão de riscos, mesmo não sendo ainda um assunto muito difundido e apesar da maioria das instituições não possuir um sistema de gestão de riscos. As ações e os controles apresentados por meio da pesquisa demonstram a intenção dos gestores de praticar a gestão de riscos nas suas instituições.

O presente trabalho procurou observar questões que estão ligadas diretamente à gestão das IES, e que são de fundamental importância para a permanência das instituições na prestação de serviços de ensino superior. Pode-se inferir que os gestores das IES devem ter como foco na sua gestão a preocupação com os diversos tipos de riscos que as instituições estão expostas.

Rev. GUAL., Florianópolis, Edição especial 2011, p.70-93. 


\section{REFERÊNCIAS}

ALMEIDA, Domingues Miguel Sequeira de. Gestão de risco e governo das sociedades. Revista Auditoria Interna, Lisboa, ano 6, n. 22, p. 9-14, out./dez. 2005.

BALLOU, Brían; HEITGER, Dan. A building-block approach for implementing COSO's enterprise risk management-integrated framework. Management Accounting Quarterly, Montvale, v. 6, n. 2, p. 1, 2005.

BEUREN, Ilse Maria (Org.) et al. Como elaborar trabalhos monográficos em contabilidade: teoria e pratica. 3. ed. atual. de acordo com as Normas da ABNT: NBR 6034: 2004 NBR12225: 2004, São Paulo: Atlas, 2006.

BRITO, Osias. Controladoria: de risco-retorno em instituições financeiras. São Paulo: Saraiva, 2003.

Contribuição ao estudo de modelo de controladoria de risco-retorno em bancos de atacado. Tese (Doutorado em Contabilidade), Universidade de São Paulo, São Paulo, 2000 .

CAMPBELL, Susan. COSO: benefit or bale? Intheblack, Austrália, v. 75, n. 8, p. 58-62, Sep., 2005.

CARVALHO, Luiz Nelson Guedes de. Uma contribuição à auditoria do risco de derivativo. Tese (Doutorado em Contabilidade), Universidade de São Paulo, São Paulo, 1999.

CERVO, Amado Luiz; BERVIAN; Pedro Alcino. Metodologia científica. 5. ed. São Paulo: Prentice Hall, 2002.

COMMITTEE OF SPONSORING ORGANIZATIONS OF THE TREADWAY

COMMISSION - COSO - Internal Control - Integrated Framework. Executive Sumary. Washington, 1992.

.Enterprise Risk Management Framework. Executive Sumary. Washington, 2004.

CROUHY, Michel; GALAI, Dan \& MARK, Robert. Gerenciamento de Risco: abordagem conceitual e prática: uma Visão Integrada dos Riscos de Crédito, Operacional e de Mercado. Rio de Janeiro: Qualitymark, São Paulo: SERASA, 2004.

DAVIS, Marcelo David. A importância da aplicação da gestão de riscos nos sistemas de controle interno da administração pública. Dissertação (Mestrado em Ciências Contábeis), Universidade do Estado do Rio de Janeiro, Rio de Janeiro, 2006.

DAVIS, Marcelo David; BLASCHEK, José Roberto de Souza. Deficiências dos sistemas de controle interno governamentais atuais em função da evolução da economia. In: 
CONGRESSO USP DE CONTROLADORIA E CONTABILIDADE, 6, 2006, São Paulo. Anais... São Paulo.

FERREIRA, Igor Rocha. Earnings at risk para as instituições não financeiras e as exigências da Lei Americana Sarbanes-Oxley. Dissertação (Mestrado em Finanças e Economia Empresarial) - Fundação Getúlio Vargas, Rio de Janeiro, 2005.

GATTO, Rodrigo Lopes. Técnicas de gestão de risco de mercado e manutenção da liquidez numa cooperativa de crédito. Dissertação (Mestrado em Engenharia da Produção) Universidade Federal de Santa Catarina, Florianópolis, 2004.

GOMES, P. H. V. ; PONTE, V. M. R. ; FERREIRA, J. H. M. ; ROCHA, D. C. . Análise do Nível De Adesão ao Disclosure do Risco Operacional pelos Bancos com Ações Negociadas na BM\&FBovespa. In: $11^{\circ}$ Congresso USP Controladoria e Contabilidade, 2011, São Paulo. $11^{\circ}$ Congresso USP Controladoria e Contabilidade, 2011.

MARSHALL, Christopher. Medindo e gerenciando riscos em instituições de ensino superior. Rio de Janeiro: Qualitymark, 2002.

MARTIN, Nilton Cano; SANTOS, Lílian Regina; DIAS FILHO, José Maria. Governança empresarial, riscos e controles internos: a emergência de um novo modelo de controladoria. Revista Contabilidade \& Finanças, São Paulo, n. 34, p. 7-16, jan./abr. 2004.

MORAES, José Castro Fróes de. Análise da eficácia da disseminação de conhecimentos sobre controles internos após sua implementação no Banco do Brasil. Dissertação (Mestrado em Engenharia da Produção), Universidade Federal de Santa Catarina, Florianópolis, 2003.

PAULO, Wanderlei Lima de. et al. Controles internos: uma metodologia de mensuração dos níveis de controle de riscos empresariais. Revista Contabilidade \& Finanças, São Paulo, n. 43, p. $49-60$, jan./abr. 2007.

RICHARDSON, Roberto Jarry. Pesquisa Social: métodos e técnicas. São Paulo: Atlas, 1999.

RIZZATTI, Gerson. Categorias de análise de clima organizacional em universidades federais brasileiras. Tese (Doutorado em Engenharia da Produção), Universidade Federal de Santa Catarina, Florianópolis, 2002.

ROZO, José Danúbio. Controle interno como variável explicativa para o sucesso

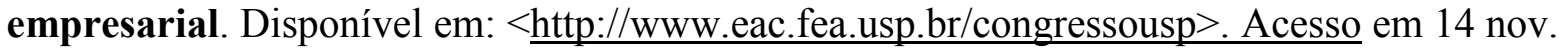
2006.

SANTOS, Antonio Raimundo dos. Metodologia científica: a construção do conhecimento. Rio de Janeiro, DP \& A, 1999. 
SANTOS, Carlos; VASCONCELOS, André; TRIBOLET, José. Da framework CEO à auditoria de sistemas de informação. Disponível em: $<\mathrm{http}: / \mathrm{www}$.inesc-

id.pt/pt/indicadores/Ficheiros/2114.pdf $>$. Acesso em: 17 out. 2011. 


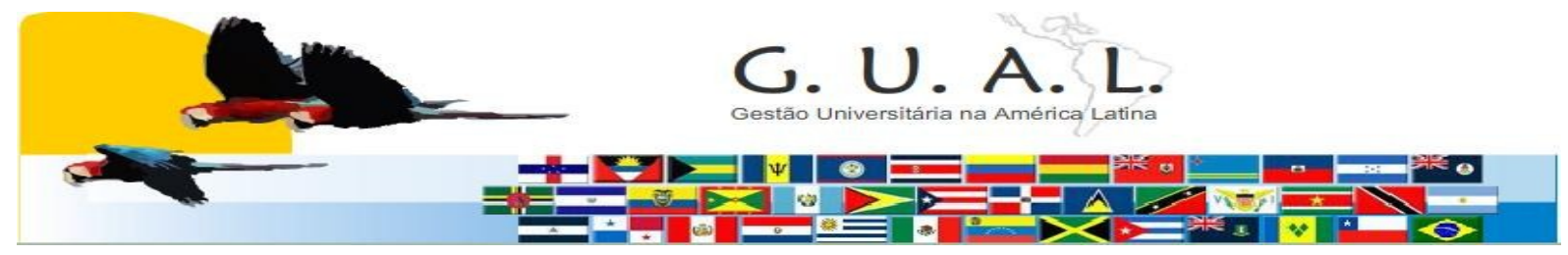

ISSN 1983-4535

\title{
RISK MANAGEMENT IN THE UNIVERSITIES AND UNIVERSITY CENTERS OF THE STATE OF SANTA CATARINA
}

\author{
Célia de Souza Sedrez, Bachelor \\ Centro Universitário de Brusque - UNIFEBE \\ celia@unifebe.edu.br
}

Francisco Carlos Fernandes, Doctor

Universidade Regional de Blumenau - FURB

franciscofernandes@furb.br

\begin{abstract}
This paper analyzes and describes the adaptation and application of risk management and internal controls in Higher educational institution (HEI) of the Santa Catarina State as a necessary support to every institution's Control. The research applied the quantitative and cross section methods. In relation to its objectives this is descriptive research with the population defined by the 5 University Centers and 12 Universities of the Santa Catarina State. It was verified that most of the preoccupations of the managers in therms of risks stays in the categories of strategic risks (main factor: reduction of the number of students) and finantials (main factor: default). Finally it was concluded that the ISE are worried about risk management, even though this subject is not appropriately discussed and, in most of the institutions, due to the lack of a specific support system to the risk management, the actions and the adopted controls show the disposition of the managers of practicing the risk management.
\end{abstract}

Keywords: Risk management. Higher educational institution. Internal controls. 